\title{
LA HISTORIOGRAFÍA SOBRE ARQUITECTURA TEMPLARIA EN LA PENÍNSULA IBÉRICA ${ }^{1}$
}

\author{
THE HISTORIOGRAPHY OF TEMPLAR ARCHITECTURE \\ IN THE IBERIAN PENINSULA
}

Resumen: La importancia del patrimonio monumental de la Orden del Temple en la península Ibérica (principalmente castillos) no ha tenido un tratamiento equivalente en la historiografía. En la segunda mitad del XIX, los románticos mezclaron realidad y ficción al atribuir a las capillas templarias la planta redonda como modelo único. En 1954, un artículo de Lambert sobre la arquitectura de los templarios, deshizo el entuerto y sentó las bases para su estudio científico. Afortunadamente, en las últimas décadas, el estudio de este patrimonio ha entrado en la normalidad académica que le correspondía dentro de la Historia del Arte.

Palabras clave : Templarios, Arquitectura, Historiografia.
JOAN FUGUET SANS

Escola Superior de Conservació i Restauració de Béns Culturals de Catalunya, Barcelona
Abstract: The importance of the historical monument heritage of the Temple Order in the Iberian Peninsula (mainly castles) has been treated differently within historiography. In the second half of the nineteenth century, the Romance movement mixed fact and fiction, attributing a round floor plan to all Templar chapels. In 1954 an article by Lambert on Templar architecture broke with this mistaken theory and established the basis for its scientific study. Fortunately, in recent decades the study of this heritage has achieved the academic recognition it deserved within History of Art.

Keywords: Templars, Architecture, Historiography

\section{SUMARIO}

1. Introducción.- 2. Las primeras referencias sobre la arquitectura templaria, el eco de las teorías románticas en la península Ibérica.- 3. La historiografía de la segunda mitad del siglo XX. Las nuevas orientaciones de Élie Lambert.- 4. Los estudios recientes.

${ }^{1}$ Este artículo fue presentado a las «Terceras Jornadas Internacionales "Medio siglo de estudios sobre las Cruzadas y las Órdenes Militares, 1951-2001”, Teruel, Mora de Rubielos, Rubielos de Mora, La Iglesuela del Cid, Cantavieja, 19-25 de julio de 2001», en homenaje a Sir Steven Runciman (1903-2000), Universidad de Zaragoza y Ayuntamiento de Teruel. 


\section{INTRODUCCIÓN}

A pesar de la importancia histórica de la orden del Temple en la Península Ibérica y del abundante patrimonio monumental conservado, éste no ha gozado, dentro del contexto de la historia del Arte, de la atención que han merecido las construcciones de otras órdenes religiosas, como por ejemplo los cistercienses o los mendicantes.

Hasta hace relativamente poco, era usual que los monumentos templarios principales fueran tratados como ejemplos de un determinado estilo artístico (románico, gótico, ....) o de un tipo de construcción (arquitectura militar, religiosa), sin que se hiciera referencia a su pertenencia al Temple. Y, lo que es peor, se seguían utilizando como válidas ciertas afirmaciones de los románticos, tiempos ha superadas, en el momento de atribuir a los templarios edificios de origen desconocido y, sobre todo, capillas funerarias de planta circular.

Actualmente a nadie se le escapa la importancia histórica de las órdenes religioso-militares y la de su patrimonio monumental; los estudios sistemáticos promovidos desde la Universidad en las últimas décadas han colaborado a darlo a conocer. Pero, si bien es cierto que recientemente este patrimonio ha sido objeto de estudios monográficos y ha sido incluido en obras generales $^{2}$, tal vez no se ha insistido suficientemente en presentarlo con carácter monográfico dentro de un contexto histórico de las órdenes militares que permita verlo y relacionarlo, no tan sólo con los ejemplos contemporáneos de arquitectura no templaria de nuestro país, sino también con ejemplos similares de las órdenes militares de otros países y, sobre todo, en el caso de la arquitectura militar con la homónima de los cruzados de Tierra Santa. Esto es lo que hicimos en nuestra tesis doctoral $^{3} \mathrm{y}$ en numerosos artículos posteriores ${ }^{4}$.

Dicho esto, intentaremos explorar la historiografía sobre arte del Temple en la Península desde el Romanticismo hasta la actualidad. No se nos escapa que resultará desigual y fragmentario a causa del diferente tipo de aproximaciones que se han llevado a cabo sobre este tema.

\footnotetext{
${ }^{2}$ N. De Dalmases; A. José I PITARCh, L'època del Cister, en Història de l'Art Català, II, Barcelona, Ed. 62, 1985, pp. 91-99. ${ }^{3} \mathrm{~J}$.

${ }^{3} \mathrm{~J}$. FugUet SANS, L'arquitectura dels templers a Catalunya, Barcelona, Rafael Dalmau, Ed.,

${ }^{4}$ Véanse las notas 101, 104 y 105. 


\section{LAS PRIMERAS REFERENCIAS SOBRE ARQUITECTURA TEMPLARIA. EL ECO DE LAS TEORÍAS ROMÁNTICAS EN LA PENÍNSULA IBÉRICA}

En la literatura romántica, a partir del segundo tercio del siglo XIX, empiezan a aparecer textos que se refieren a construcciones de la orden del Temple. Algo más tarde, y en evidente relación con los primeros escritos, los arquitectos historiadores formularán una teoría artístico-simbólica sobre las capillas templarias de planta central. Finalmente, la misma dinámica historicista neomedieval impulsará los primeros escritos histórico-artísticos sobre construcciones templarias.

Curiosamente, tan sólo fortalezas y algunas iglesias, sobre todo las de planta central, merecieron la atención de historiadores, poetas y escritores; el resto de construcciones de la orden (casas de campo, residencias urbanas, construcciones industriales...) jamás fueron consideradas ni tratadas. Con respecto a los comentarios, siempre idealizados, que hicieron los escritores románticos de edificios templarios, cabe subrayar que siempre se trató de ruinas de iglesias o de fortalezas guerreras, lo cual muestra la pervivencia del recuerdo de la participación de los monjes-soldados en la Reconquista ${ }^{5}$. En muchos de estos casos, se trataba de atribuciones falsas: buena parte de edificios de origen dudoso o ignorado eran fácilmente puestos en la nómina de las construcciones templarias.

El poeta G.A. Bécquer (1836-1870), en dos de sus leyendas ("El Monte de las Ánimas" y "El rayo de luna") atribuye a los templarios edificios religiosos ruinosos de Soria. A pesar de tratarse de textos cortos, parece que en la primera leyenda se refiere a una dependencia de la iglesia de San Polo y en la segunda al monasterio de San Juan de Duero, ambas ajenas al Temple $^{6}$. Pero no siempre los románticos recurrieron a la atribución popular. En la más importante novela histórica del romanticismo español, El señor de Bembibre (1844), E. Gil y Carrasco, muestra con descripciones arquitectónicas de gran exactitud los castillos de Ponferrada y Cornatel $^{7}$, pertenecientes al señorío templario del Bierzo.

En la Corona de Castilla, mucho más que en la Corona de Aragón, la asignación arbitraria de edificios a la orden del Temple ha estado y sigue estando muy extendida ${ }^{8}$. Por lo que respecta a Castilla, la escasez de

\footnotetext{
${ }^{5}$ Sobre este tema, véase, Wido HEMPEL, Los jacobinos del siglo XIII. Un simulacro de proceso en plena Edad Media y sus consecuencias en la historia de las ideas y en la literatura de la Ilustración y el Romanticismo europeos, en Entre el Poema de Mío cid y Vicente Aleixandre, Barcelona, Ed. Alfa, 1983, pp. 61-105.

${ }^{6}$ Una y otra pertenecieron a la orden del Hospital de San Juan de Jerusalén (véase, G. MARTínez DíEz, Los templarios en la Corona de Castilla Burgos, 1993, pp. 116-121), hecho que muestra otra confusión habitual en las atribuciones de las obras del Temple.

${ }^{7}$ Véase sobre ello, la Introduccion de J.L. PICOCHE a la edición crítica de El señor de Bembibre, Madrid, Clásicos Castalia, 1989.

${ }^{8}$ Véanse los comentarios al respecto de G. MARTíNEZ DÍEZ, Los templarios en los reinos de España, Barcelona, Ed. Planeta, 2001, pp. 116-121, 153, 166...
} 
documentación ${ }^{9}$ aumenta la posibilidades de error, ya que la mayor parte de atribuciones formaban parte de tradiciones populares antiguas ${ }^{10}$. Aunque este argumento resulta también válido para Cataluña, las adscripciones erróneas son menos frecuentes a causa de la existencia de abundante documentación ${ }^{11}$.

La atribución al Temple de las capillas de plan central llegó a la península al caer el siglo XIX (1998) de la mano del arquitecto historiador Vicente Lampérez y Romea ${ }^{12}$, quien, cautivado por las teorías románticas de Viollet-le-Duc $(1868)^{13}$, llevó a cabo una labor intelectual e interpretativa de gran alcance al aplicar la teoría geométrico-simbólica del arquitecto francés a las capillas de la Vera Cruz (Segovia) y de Eunate (Navarra), edificios ambos de planta radial atribuidos a los templarios. Como hiciera Viollet con las capillas de París y Laon, Lampérez analizó la planta y el alzado de la Vera Cruz a partir de un triángulo equilátero inscrito en una circunferencia. Respecto al octógono de Eunate, interpretó la arquería perimetral como los restos de una galería que habría rodeado un atrio descubierto, solución empleada, según él, en las iglesias templarias: «Sabido es que muchos edificios de Templarios y Sanjuanistas, imitando el Santo Sepulcro de Jerusalén tienen un doble recinto concéntrico». Unos años más tarde S. Huici $(1923)^{14}$ haría lo mismo con la capilla, también navarra, de Torres del Río.

Fue así como durante las primeras décadas del siglo XX, las capillas radiales de la Vera Cruz, Eunate y Torres del Río, se convirtieron en sólidas representantes de la fórmula utilizada por los templarios para imitar y rememorar el Santo Sepulcro de Jerusalén. Pero a diferencia de lo que sucedió con las capillas francesas de París y Laon, donde la teoría geométricosimbólica de Viollet iba unida a una indiscutible filiación templaria, en el caso de España el origen templario de las tres capillas fue muy pronto descartado 0 , en el mejor de los casos, cuestionado ${ }^{15}$. Pero, a pesar de la falta de rigor

\footnotetext{
${ }^{9}$ En el estudio de G. Martínez Díez sobre los templarios en el Reino de Castilla (cit. n. 6) son continuas las referencias a esta falta de documentación, por ejemplo, pp. 67-69.

${ }^{10}$ En el siglo XVII Diego de Colmenares da fe de este fenómeno a propósito de algunos edificios de la điócesis de Segovia entre ellos la famosa Vera Cruz [D. DE COLMENARES, Historia de la insigne ciudad de Segovia, Segovia, $1637, \mathrm{p}, 253$-citado por E. LAMBERT, L'architecture
des templiers, "Butlletin Monumentale», 112 (Paris, 1954), pp. 7-60 y 129-166-.

${ }^{11} \mathrm{El}$ Archivo de la Corona de Aragón, de Barcelona, conserva el fondo documental templario más rico de Occidente.

${ }^{12} \mathrm{~V}$. LAMPÉREZ Y ROMEA, Los trazados geométricos de los monumentos españoles de la Edad Media: la iglesia de los Templarios en Segovia, «Boletín de la Sociedad Española de Excursiones». VI (1898-1899), pp. 36-39; IDEM, La iglesia de los Templarios de Eunate (Navarra), «Cultura Española» (Madrid, 1907); IDEM, Historia de la arquitectura Cristiana española en la Edad Media, I, Barcelona, 1909, pp. 603-607.
Edura Español (Madrid, 1907); IDEM, Histor

${ }^{13}$ Nos referimos a la teoría desarrollada en su famoso Dictionnaire (1868), que significó la primera lectura simbólica de una capilla templaria de planta central (ejemplificada con las de París y Laon).

${ }^{14} \mathrm{~S}$. HuicI Iglesia de Templarios en Torres del Río (Navarra), «Arquitectura», 52 (Madrid, 1923), pp. 253-258.

${ }^{15}$ En 1919, un vehemente estudio del arquitecto Cabello (L. M. CABELlo LAPIEDRA, La Vera Cruz de Segovia nunca fue de Templarios, en «Arquitectura», 14-2, (Madrid, 1919), p. 155) parecía demostrar que la capilla segoviana había sido construida por los caballeros del Santo Sepulcro. También era puesta en duda la "templariedad" de la rotonda de Torres del Río en este caso por Torres Balbas (T. [orres], L. [eopoldo]: Nota. [al artículo de S. HUIZI, Iglesia de Templarios de Torres del Río], "Arquitectura», 52, (Madrid, 1923), pp. 258-259. Años más tarde
} 
històrico que presentaba en su base el estudio de las capillas ${ }^{16}$ y el hecho de que fuera tan sólo aplicable a una pequeña parte del conjunto monumental del Temple, el artículo fue sin duda, el capítulo más interesante que se escribió sobre la arquitectura templaria hasta la primera mitad del siglo XX.

Más allá del episodio romántico de las capillas de planta central no puede decirse que la arquitectura de los templarios hubiera interesado demasiado a los historiadores del arte de fines del XIX y primeras décadas del $\mathrm{XX}$. Los textos históricos aparecidos en esta época suelen ser relatos cortos de excursiones científicas, guías ilustradas, compendios generales de historia del arte, inventarios generales de castillos... y, excepcionalmente, alguna monografía local. El conjunto es muy heterogéneo y de desigual valía; casi todos los estudios están afectados, en mayor o menor grado, por el peso de la tradición con respecto a las atribuciones. Sin embargo, muchos de esos textos serán los primeros comentarios importantes de historia de la arquitectura, aún hoy válidos, que se han dedicado a los monumentos templarios.

En tierras de la histórica Corona de Castilla se empiezan a encontrar noticias sobre monumentos templarios en textos historicistas, más o menos fiables, de las famosas guías ilustradas "Recuerdos y bellezas de España" $(1839-1865)^{17}$; reseñas de excursiones científicas, en el "Boletín de la Sociedad Castellana de Excursiones"18; artículos con alguna intención arquitectónica en el "Boletín de la Real Academia de la Historia"19; en revistas científicas regionales, como la «Revista de Estudios Extremeños ${ }^{20}$;

(1951), el también arquitecto Cabello Dordero, con motivo de haber restaurado la iglesia de la Vera Cruz realizó un estudió, aparentemente definitivo, que partía de un supuesto documento medieval, para concluir que la Vera Cruz había sido construida por los templarios (J.CABELLO

ORDERO, La iglesia de la Vera Cruz, «Estudios Segovianos», 3, (Segovia, 1951), pp. 425-448).

${ }^{16}$ La falta de rigor científico también afectó a Viollet, quien se excedió al afirmar que las capillas de todos los conventos templarios, de Oriente y Occidente, se habían construido en planta central para imitar y rememorar el famoso edificio que los primeros cristianos habían levantado en el lugar del Santo Sepulcro de Jerusalén.

${ }^{17}$ Concebidas por el dibujante F.X. Parcerisa, con quien colaboraron el literato P. Piferrer y los historiadores fosé $\mathrm{M}^{\mathrm{a}}$ Quadrado y F. Pi y Margall, el año 1853, fue publicado uno de Castilla la Nueva y en 1865 otro dedicado a Sạlamanca, Avila y Segovia. Entre 1880 y 1891 , bajo la responsabilidad de J.M. Quadrado, se hizo una șegunda edición, ampliada, bajo el título: España, sus monumentos y artes, su naturaleza e historia, de la cual aparecieron varios volúmenes sobre la antigua corona de Castilla (J.M. QUADRADO, España, sus monumentos y artes, su naturaleza $e$ historia. Valladolid, Palencia y Zamora, Barcelona, 1984; IDEM, España (...). Asturias y León, Barcelona, 1885; e IDEM, España (...). Salamanca, Avila y Segovia, Barcelona, 1885; N. RABAL, España (...).Soria, Barcelona, 1889.

${ }^{18}$ Con aportaciones como la de V. LAMPÉREZ Y ROMEA, La iglesia de los templarios de Villalcázar de Sirga, «Boletín de la Sociedad Castellana de Excursiones», XI, (Madrid, 1903), pp. 172-176; T. RAMIREZ, San Juan de Otero iglesia de Templarios, "Boletín de la Sociedad Castellana de Excursiones», III (Madrid, 1907/1908), pp. 33-35.

${ }^{19}$ J.R. MÉLIDA, La iglesia de Santa María Magdalena de Zamora «Boletín de la Real Academia de la Historia» LVII, (Madrid, 1910), pp.101-106: F. FITA, Coria compostelana templaria, «Boletín de la Real Academia de la Historia», 61, (Madrid, 1912), pp.346-351.

${ }^{20} \mathrm{~A}$. COVARSI, Extremadura artística. Los monumentos histórico-artísticos de la província de Badajoz, «Revista del Centro de Estudios Extremeños», II, VII, X-XI y XII (Badajoz), 1929-1939; G. VELO Y NIETO, Coria y los templarios. Don Fernando II de León reconquista los territorios de la antigua diócesis cauriense, «Revista de Estudios Extremeños», 5 (Badajoz, 1949), pp.281302 . 
en el «Catálogo Monumental de España ${ }^{21}$; en la «Geografia General de España» dirigida por Carreras Candi.

Los primeros estudios que podemos considerar de historia del arte sobre castillos e iglesias templarias, verdaderas o atribuidas, aparecen en algún artículo y en las mismas obras generales en que Lampérez Romea $(1903,1909 \text { y } 1922)^{22}$ abordara el tema de las capillas de planta central. Los edificios ahí estudiados son tratados en el contexto general de los estilos y tipologías medievales propuestos por el autor; en ellos, la metodología científica empleada por Lampérez es aún hoy válida en muchos aspectos.

Tal vez una de las primeras monografías locales dedicadas a una fortaleza templaria es la que escribió José $\mathrm{M}^{\mathrm{a}}$ Luengo $^{23}$ sobre el castillo de Ponferrada (capital templaria del Bierzo y enclave importante del Camino de Santiago). Es un estudio metodológicamente correcto, en el cual, entre otras cosas, se discute con objetividad científica la atribución al Temple de un símbolo tan susceptible de esoterismo como la Thau que aparece en varios lugares del castillo. Unos años más tarde, en 1932, aparece el famoso inventario «Castillos de España» de C. Sarthou Carreres que aún sigue reeditándose, cada vez con más errores. Su edición príncipe ${ }^{24}$ fue tal vez la primera obra general dedicada al tema de los castillos españoles. En él continua con metodología histórico-descriptiva de las guías, por consiguiente, tiene escasa incidencia en la historia de la arquitectura. Sin embargo, en la introducción hace una mención específica a las fortalezas templarias, que ahora puede parecer un tanto ambigua, pero que no debió serlo en su momento, ya que establece diferencias entre «castillos monacales» $\mathrm{y}$ «castillos fortaleza» refiriéndose a las fortalezas templarias, frente a los castillos en general. Con el primer calificativo se refiere a Peníscola, Villarejo de Salvanés, Gardeny, Monzón; con el segundo, a Ponferrada, Jaramilla, Miravet, Gardeny (sic) y Torija. Como era previsible, alguno de los ejemplos (Villarejo, Jaramilla, Torija) eran atribuciones infundadas, pero los demás son efectivamente importantes castillos templarios. Un error destacable es hablar de dos castillos de Gardeny, ambos en la provincia de Lérida (el «fuerte de Gardeny», en una colina cercana a la ciudad, y el castillo de «Gardeny» frente a la Zuda). Es así mismo negativamente destacable la poca información que tiene del castillo de Miravet (Ribera d'Ebre, Tarragona), que sitúa en la provincia de Lérida. Por el contrario, la fortaleza de Peníscola es evocada con un largo y documentado artículo.

\footnotetext{
${ }^{21}$ M. GóMEZ MORENO Catálogo Monumental de España Provincia de León, Ministerio de Instrucción Pública y Bellas Artes, Madrid, 1925; J.R. MÉLIDA, Catálogo Monumental de España. Provincia de Badajoz, Madrid, 1925; R. NAvARro GARCÍA: Catálogo Monumental de España. Provincia de Palencia, Palencia, 1939.

${ }^{22} \mathrm{~V}$. LAMPÉREZ y ROMEA, La iglesia de los Templarios de Villalcázar de Sirga (Palencia) «Boletín de la Sociedad Española de Excursiones», 11 (Madrid, 1903), p. 145; y las obras citadas en la nota 11 .

${ }^{23}$ J.M a LUENGo y MartíneZ, Monumentos militares leoneses. El castillo de Ponferrada, León, 1929.

${ }^{24}$ C. Sarthou Carreres, Castillos de España, Valencia, 1932.
} 
Una labor pionera en lo que al estudio de castillos se refiere es la que en el país valenciano realizó, a partir de 1915, L. Tramoyeres desde la revista «Archivo de Arte Valenciano» donde, como es lógico, dedica especial atención al castillo de Peníscola ${ }^{25}$. Es un detalle a subrayar que cuando Tramoyeres y Sarthou escriben sobre Peníscola ignoran prácticamente toda la historia referente a la Orden del Temple y hablan poco de la arquitectura. En ambos artículos acapara la atención la figura del papa Luna.

Son escasos los textos dedicados al patrimonio templario de la isla de Mallorca, donde el Temple tuvo importantes edificios, en la ciudad de Palma y en Pollença. En 1882, el Archiduque Luís Salvador, en uno de sus famosos libros dedicados a las islas Baleares ${ }^{26}$, describió con suma precisión la fortaleza de Gumara de la ciudad de Palma y su oratorio, que había sido sede de la encomienda insular. Pocos años después, en 1885, la recién fundada Sociedad Arqueológica Luliana recogía en su Boletín el resultado de una visita científica realizada al mismo monumento ${ }^{27}$. Se refirieron también a este edificio P. Piferrer y J.M. Quadrado en el volumen Islas Baleares de la guía ilustrada España en sus monumentos y sus artes, su naturaleza e historia publicado en 1888. Por lo que respecta al patrimonio monumental templario de la villa de Pollença, (iglesia parroquial y casa del Temple, ambos sustituidos por edificios sanjuanistas) fue tratado, en 1897/98, por el erudito canónigo Dr. Mateu Rotger i Capllonch, en su Historia de Pollensa ${ }^{28}$.

En Cataluña, durante este periodo inicial de la historiografía, también había sido habitual que algunos edificios antiguos de origen dudoso o desconocido fuesen considerados templarios. Pero a diferencia de lo que sucedió en Castilla, no parece que las teorías románticas de las capillas radiales afectaran a los historiadores. En el siglo XVIII se atribuye al Temple del castillo real de Lérida (la Zuda) ${ }^{29}$, error que no cometerán los historiadores del XIX. A fines del XIX o principios del XX, son atribuidas al Temple algunas iglesias de origen ignorado ${ }^{30}$, cuyo origen se ha podido establecer

${ }^{25}$ L. Tramoyeres Blasco, Castillos valencianos, «Archivo de Arte Valenciano» (Valencia, 1918), pp. 48-61.

${ }^{26}$ Die Stadt Palma, Leipzig, 1882 (traducido al español en 1954).

${ }^{27}$ Visitas al oratorio del Temple, «Boletín de la Sociedad Arqueológica Luliana», 1/4, pp. 4-6. 25-38.

${ }^{28} \mathrm{M}$. Rotger y CAPllonch, Historia de Pollensa, Pollença, 1995 ( $3^{\mathrm{a}}$ ed.), I-III, vol. II, pp.

${ }^{29}$ Véase, J. FUGUET SANS, L'arquitectura dels templers, cit. n. 3, p. 43, nota 5; IDEM, Apunts sobre realitat $i$ mite en el patrimoni arquitectonic de l'Orde del Temple a Catalunya, en Escola Catalana, 298 (Barcelona, març, 1993), pp. 17-21.

${ }^{30}$ En guías de excursiones o en obras generales de historia suelen aparecer como iglesias templarias Santa Maria del Miracle, levantada en la arena del anfiteatro romano de Tarragona y el santuario de Paretdelgada en la Selva del Camp (Tarragona). Sobre el primer caso, vease, J.F. AlBINYANA Y DE BORRÀs; A. DE BOFARULL Y DE BROĊ̀, Tarragona monumental o sea descripción de todas sus antigüedades y monumentos, Tarragona, 1849 , $\mathrm{p}$. 126; J. HERNÁNdescripción de todas sus antigüedades y monumentos, Tarragona, $1849, \mathrm{p}, 126 ; \mathrm{J}$. HER
DEZ SANAHUJA: El indicador arqueologico de Tarragona, Tarragona $1867, \mathrm{p}$. $148 ; \mathrm{E}$. DEZ SANAHUJA: El indicador arqueologico de Tarragona, Tarragona, 1867, p. 148; E. . IDEM, Informe sobre Santa Maria del Milagro, "Boletín Arqueológico», 6 (Tarragona, 1914); A. DEL ÁRC, Paseos arqueológicos por la diocesis de Tarragona I. Iglesia de N. S. Del A. DEL ARCO, Paseos arqueologicos por la diocesis de Tarragona I. Iglesia de N. S. Paretdelgada, J. PIÉ FAIDELLA, Relación histórica del santuario de Paret Delgada, Tarragona 1896, pp. 12-13; E. MORERA Y LLAURADÓ, Província de Tarragona, dentro de: F. CARRERAS 
posteriormente ${ }^{31}$, pero en ningún momento se hablará de capillas de planta central.

Uno de los primeros textos que se refieren a un castillo-encomienda de los templarios catalanes es el capítulo que dedicó al castillo de Barberá (Tarragona) el párroco Josep Porta y Blanch (1905), dentro de una monografía local de su parroquia ${ }^{32}$. Aún hoy sorprende la erudición mostrada por aquel humilde clérigo quien, después de abundar en la bibliografía general a la sazón existente (Tómic, Zurita, Balari y Jovany, Auléstia y Pijoan...) ofrece numerosas fichas del Archivo del Gran Priorato de Cataluña (entonces custodiado por las religiosas sanjuanistas de Sant Gervasi de Cassoles, de Barcelona) y de su propio Archivo Parroquial, del cual entre muchas referencias históricas reproduce un interesante inventario del castillo, del siglo XVI, donde figuran descritas muchas dependencias de la fortaleza templaria, unas desaparecidas, otras aún existentes.

Los estudiosos catalanes no establecen diferencias entre las iglesias templarias, atribuidas o ciertas, y las contemporáneas ajenas a la orden. Es interesante destacar que en uno de los relatos de excursiones científicas del Butlletí del Centre Excursionista de Catalunya, el historiador y geógrafo F. Carreras Candi (1908) describe el castillo y la iglesia de los templarios de Gardeny (Lérida) prestando especial atención a su arquitectura ${ }^{33}$.

Diez años después, Puig y Cadafalch $^{34}$ (1918), el más importante historiador de la arquitectura medieval catalana, hará una exhaustiva descripción y análisis del mismo monumento. Su iglesia, de una sola nave con ábside, es presentada como un ejemplo representativo de la escuela provenzal con gran influencia cisterciense. En el capítulo dedicado a los monasterios, el autor subraya el caracter militar de los conventos templarios (como haría años más tarde Lambert): els monjos del Temple eren militars y habitaven, més que en un monastir, seguint la disposició tradicional, un veritable castell. Según Puig, Gardeny es la fortaleza templaria catalana que ha llegado en mejor estado a nuestros días. Sus comentarios son muy significativos porque

Y CANDI (dir.), Geografia General de Catalunya, Barcelona, s/d, p. 348).

${ }^{31} \mathrm{La}$ paternidad templaria sobre la iglesia tarraconense del Miracle fue desmentida por Sanç Capdevila (S. CAPDEVILA: El temple de Santa Maria del Miracle de Tarragona, Tarragona, 1924). A pesar de ello, la tradición sigue afectando trabajos recientes (N. DE DALMASES; A. JOSE I PITARCH, L'época del Cister, dentro de Història de l'Art Català, Ed. 62, Barcelona, 1985, v. 2 , p. 96). Sobre el santuario de Paretdelgada sigue la incógnita (veáse, J. FUGUET SANS, arquitectura dels templers, cit. n. 3, pp. 243-250).

${ }^{32} \mathrm{~J}$. PORTA I BLANCH, Arreplec de dades per a la història de Barberà, Ajuntament de Barberà de la Conca, 1984, pp. 87-99.

${ }^{33}$ «Los templers al construir la fortalesa de Gardeny, li donaren la forma cúbica, cuidant de no rompre, ab cap torre sobresortint, la seva feixuga silueta. L'església molt propera al castell n'estava separada, si bé sempre dintre'l conjunt del seu amurallament (...) Al interior del castel és interessant una espayosa nau de volta apuntada (...) [la capilla] conserva sa senzilla porta d'entrada romànica, donant al pati exterior, $y$ les arcades gotiques de la seva nau també s'utilitsen per allotjament dels soldats...” [F. CARRERAS Y CANDI, Excursions per la Catalunva aragonesa y provincia d'Osca. I, Gardeny, Fraga, Sixena y Sarinvena, «Butlletí del Centre Excursionista de Catalunya», XVIIII/162, (Barcelona, 1908), pp. 193-200].

${ }^{34}$ J. PUIG Y CADAFALCH; A. DE FALGUERA; J. GODAY, L'arquitectura romànica a Catalunya, Barcelona, IEC, 1918, III, pp. 422-425 y 576-578. 
representan una manera positivista y empírica de estudiar la arquitectura que no cae en interpretaciones subjetivas pues en ningún momento habla de las teorías de Viollet-le-Duc y de Lampérez sobre las plantas circulares. Incomprensiblemente un autor tan brillante y prolifero ignoró el castillo de Miravet de la tarraconense Ribera d'Ebre ${ }^{35}$.

Aunque lo ignoramos, es presumible que en Portugal también se atribuyeran edificios antiguos a los templarios. Así mismo, desconocemos si en el país vecino hicieron mella las teorías de Viollet o de Lampérez sobre las capillas de planta central; la existencia en la fortaleza templaria de Tomar de uno de los oratorios de planta circular más representativas de Occidente (la célebre charola), justificaría que algún autor hubiera aplicado tal teoría para la interpretación simbólica del templo. Los primeros trabajos sobre Tomar, de los cuales tenemos noticia, fueron publicados en la segunda mitad del XIX, y tienen el mismo carácter historicista de las guías ilustradas españolas ${ }^{36}$; algo más tarde, ya en el siglo XX, autores como Vieira Guimarâes $(1929)^{37} \mathrm{o}$ Lacerda Machado $^{38}$ (1936), en ningún momento se refieren a la «charola» en términos simbólicos derivados de la planta templaria. Por el contrario, son estudios que inciden en el aspecto y función militar de la capilla (que califican de «oratoiro acastelado») dentro del contexto de la gran fortaleza. Otro edificio singular $^{39}$ de los templarios portugueses, que fue objeto de pronta atención bibliográfica (en los últimos años del siglo XIX), es el castillo de Almourol ${ }^{40}$.

En resumen, en la historiografía peninsular dedicada a la arquitectura templaria de finales del XIX y de la primera mitad del XX, constatamos un interés relativo por las iglesias templarias (atribuidas o ciertas), sobretodo por las de planta central. Pero, por encima de todo, conviene subrayar la escasa atención que se dedica a la arquitectura militar y el desconocimiento total del resto de arquitectura templaria.

\section{LA HISTORIOGRAFÍA DE LA SEGUNDA MITAD DEL SIGLO XX. LAS NUEVAS ORIENTACIONES DE ÉLIE LAMBERT}

Sin menoscabo de los estudios puntuales citados, planteados ya con metodología moderna ${ }^{41}$, cualquier análisis que se haga hoy de la historiografía

\footnotetext{
${ }^{35}$ En Cataluña el olvido de las tierras del sur no es una novedad.

${ }^{36}$ I. DE VILHENA BARBOSA, Thomar. O castello dos Templários e Convento da Ordem de Christo "Archivo Pittoresco", X (Lisbo, 1867), pp. 185-187. J.A. DOS SANTOS Monumentos das Ordens Militares do Templo e de Christo em Thomar, Lisboa, 1879, pp. 27-53 y 133-141.

${ }^{37}$ V. Guimarães, Thomar, en Monumentos do Portugal, 2, Porto, 1929, pp. 35-37.

${ }^{38}$ F.S. LACERDA MACHADO, O castelo dos templários (origem da cidade de Tomar), Tomar, Comissão de Iniciativa e Turismo de Tomar, 1936.

${ }^{39}$ Por su emplazamiento, sobre una roca en medio del río Tajo.

${ }^{40}$ M. OsònIo, O casteilo de Almourol, «Revista de Engenharia Militar», I (Lisboa, 1896), pp. 199-208 y II, pp. 32-42.

${ }^{41}$ Nos referimos a incursiones puntuales de Lampérez, Puig y Cadafalch, Carreras Candi y otros autores que veremos más adelante.
} 
científica dedicada a la arquitectura del Temple en la segunda mitad del pasado siglo deberá partir del estudio publicado por Élie Lambert en 1954 sobre las capillas de planta central y la utilización que los templarios hicieron de aquella planta ${ }^{42}$. Es un artículo que pone en cuestión y descalifica los apriorismos de Viollet-le-Duc y de Lampérez sobre las capillas templarias de planta central, y aunque como estos, se limitara también a las capillas, su aportación ha de ser considerada pionera de la moderna investigación sobre la arquitectura de los templarios. Su método consistió en inventariar, con criterio científico, la arquitectura templaria conocida para demostrar que en ella la incidencia de la planta central en las capillas había sido ínfima. Simultáneamente, presentó la aparición, en el espacio y en el tiempo, de las iglesias de planta central, para demostrar que su función había sido principalmente funeraria. La conclusión fue que, con la excepción de algunos conventos principales de Oriente ${ }^{43}$ y Occidente $^{44}$, las capillas de las encomiendas templarias habían sido mayoritariamente de planta rectangular; y que gran parte de los templos de plan radial atribuidos al Temple en Francia y en España, fueron en realidad capillas funerarias ${ }^{45}$.

Finalmente afirma que la arquitectura que levantó por doquier el Temple fue esencialmente militar, tanto en los lugares belicosos como en zonas tranquilas ${ }^{46}$, afirmación que estimamos excesiva. Sin duda tal suposición deriva del estado de la cuestión en que se hallaban los estudios de arquitectura templaria en el momento de elaborar su estudio Lambert. Por aquel tiempo aún no se había llevado a cabo ninguna investigación que analizara las características y la variedad de las construcciones que habían pertenecido al Temple y prevalecía la idea de la función eminentemente militar de la orden.

Ante la imposibilidad de establecer una tipología de la arquitectura templaria por falta de estudios monográficos, Lambert optó por formular las pautas que, en su opinión, habían de regir las investigaciones futuras para llegar a un buen conocimiento del tema: relación completa de las fundaciones que hubieran pertenecido a la Orden del Temple, reseña metódica de las construcciones que habían sido efectivamente construidas por los templarios

${ }^{42}$ É. LAMBERT, L'architecture des Templiers, «Bulletin Monumental», 112, (París, 1954), pp. 7-60 y $129-166$.

${ }^{43}$ Chastel Pélerin, en el reino de Jerusalén.

${ }^{44}$ París, Londres, Tomar y algunas capillas de segundo orden en Francia e Inglaterra.

${ }^{45}$ De las capillas hispanas de planta radial atribuidas al Temple (Vera Cruz, Eunate, Torres del Río), tan solo (y con reservas) salva la segoviana Vera Cruz.

${ }^{46}$ «L'architecture des Templiers a été, comme il est logique, essentiellement une architecture militaire, architecture de forteresses et de châteaux dans les campagnes et hors des villes, architecture de residences fortifiées aux portes des villes ou dans les villes, architecture, en fin. de veritables places fortes aux sièges de leurs grands maitres. La plupart de leurs églises n'ont dété niritables places fortes aux sièges de leurs grands maîtres. La plupart de leurs églises n'on été ni rotondes ni des chapelles sur plan rayonnant. A l'interieur de leurs forteresses ou de leur châteaux, ils ont construit, en general, de petites chapelles, presque toutes sur plan basilical, qui nues-unes de ces chapelles ont été, par suite, des églises-donjons ou des salles basses de donjons proprement dits...» (E. LAMBERT, L'architecture, cit. nota 42, p. 164). 
y búsqueda e inventariación de todos los elementos arquitectónicos que pudieran subsistir.

El artículo de Lambert es muy importante por cuanto aleja definitivamente la atribución exclusiva de las iglesias templarias a la planta circular, sin embargo, sus conclusiones sobre las capillas de templarios resultan parciales pues sólo se aplican a las de los «castillos o palacios fortificados», dejando aparte las otras iglesias que no forman parte de un conjunto defensivo y que se construyeron siguiendo esquemas arquitectónicos diferentes a aquellas. Esta omisión resulta todavía más evidente si recordamos que, en conjunto, son menos numerosas las capillas de castillos que las de encomiendas rurales o urbanas; ello sin contar la gran cantidad de iglesias parroquiales de titularidad templaria, construidas en el devenir de su tarea colonizadora.

De todas formas, el estudio de Lambert abrió una vía para los estudiosos posteriores de la arquitectura religiosa templaria en el sentido que a partir de entonces se vieron libres del peso de la tradición de la planta circular y se dedicaron a describir las capillas dentro del contexto de la arquitectura religiosa de la época sin ningún «parti pris».

\section{LOS ESTUDIOS RECIENTES}

El cambio de orientación se aprecia sobre todo en el objeto de los estudios: ya no se trata de hacer teorías apriorísticas sino de la simple reseña de todos los edificios conocidos. Muchos de los estudios se circunscriben a zonas geográficas concretas que presentan una historia y una tipología arquitectónica más o menos homogénea.

Como en épocas pasadas, es Francia el país que toma la iniciativa en los estudios de este tipo. A partir de la documentación que adscribe un determinado lugar a una encomienda, se estudian los edificios que aún sobreviven de la época de dominio templario. La mayor parte de edificios analizados han sido las capillas de las encomiendas que a veces han servidotambién de iglesias parroquiales ${ }^{47}$ ya que como dice M. Melville ${ }^{48}$ : il arrive souvent qu'une chapelle soit le dernier vestige d'une commanderie perdue.

En los estudios publicados sobre la península Ibérica en las últimas décadas, observamos un primer momento en que aparecen trabajos, de mayor o menor entidad, muy condicionados por la falta de documentación y por la bibliografía de las primeras décadas de siglo. Sin embargo, en los últimos años, seguramente por influencia de la Universidad, han ido apareciendo

\footnotetext{
${ }^{47}$ Es el caso de monografías regionales: $\mathrm{CH}$. DARAS, Les commanderies et les chapelles des Templiers dans la région Charentaise, «Mémoires de la Societé Archéologique et historique de la Charente», 1954; C.M. HIGOUNET; J. GARDELLES, L'architecture des ordres militaires dan le soud-ouest de la France, en «Actes du 87e Congrès des Societés Savantes, Poitiers, 1962 Section Archéologique», París, 1963, pp. 173-194); o locales: R. OURSEL, La chapelle des Templiers de Fontenotte, "Archeologia», 11 (París, 1966), pp.73-76); F. LABORDE, L'Eglise des Templiers et les vestiges du château de Montsaunès (Haute Garonne), Saint-Girons, 1982).

${ }^{48} \mathrm{M}$. MELVILLE, Deux aspects de l'architecture des Templiers, «Archeologia», 27 (París, 1969), pp.21-28.
} 
estudios que se ajustan más a la metodología propuesta por Lambert y otros autores.

Entre los primeros cabe destacar dos trabajos diferentes en su intención y sobre todo extensión, que acusan la pobreza documental y la falta de estudios, antes mencionados, sobre la Corona de Castilla. El primero no es propiamente un estudio, pero refleja la situación referida. Se trata de un conjunto de textos redactados por M. Cocheril (1979) que acompañan las fotografías de monumentos templarios españoles. Son textos muy eruditos que pertenecen al capítulo «Ordenes Militares» de una obra colectiva ${ }^{49}$, los cuales constituyen en realidad una segunda lectura del capítulo. Sin embargo, en los monumentos españoles fotografiados y en sus correspondientes comentarios, se da la mezcla endémica de edificios templarios y falsas atribuciones. Nos referiomos a las iglesias de San Bartolomé de Ucero (Soria), Villamuriel de Cerrato (Palencia), la Vera Cruz de Segovia y la parroquial de Bosost (Valle de Arán). En todos estos ejemplos, la pertenencia al Temple ha sido cuestionada y rechazada por la historiografía posterior.

Estas mismas consideraciones cabe hacerlas al extenso trabajo realizado por Castán ${ }^{50}$ sobre la arquitectura religiosa ${ }^{51}$ de los templarios de Castilla y León, pues algunos de los edificios allí tratados serán descartados de la nómina templaria en el libro citado de Martínez Díez ${ }^{52}$. Las construcciones reseñadas por Castán corresponden a iglesias rurales, capillas de encomiendas, y también a algunas iglesias urbanas. Las conclusiones a las que llega el autor es que no hay una unidad de estilo en la arquitectura de los templarios, y que los edificios manifiestan semejanzas entre ellos a causa de la pertenencia a una misma región geográfica, ya que sus elementos característicos son los de la arquitectura románica hispánica. También apunta que en las iglesias urbanas los planes constructivos son más ambiciosos que en las rurales, ya que son los únicos ejemplos en que aparecen edificios de tres naves (el resto son de nave única). Un aspecto del trabajo de Castán que llama la atención es la minimización (y extrapolación) que hace de la arquitectura militar del Temple sin un análisis previo que lo justifique; según él "los primeros edificios que [los templarios] ocuparon en la Península fueron fortalezas, por lo que es fácil suponer que tuvieran escasa participación, por no decir que nula, en su construcción" ${ }^{33}$.

Una publicación española que desde mediados del siglo $\mathrm{XX}$ viene dedicándose a la castellología hispana es la revista «Castillos de España», órgano de la asociación «Amigos de los Castillos de España». En esta revista

\footnotetext{
${ }^{49}$ G. LEBRAS (dir.), Les Ordres religieux. La vie et l'art, I, París, Flammarion, 1979.

${ }^{50}$ J. CASTÁN LANASPA, Arquitectura templaria castellano-leonesa, Valladolid, Universidad de Valladolid, 1983.

${ }^{51}$ Aunque el título del libro es Arquitectura templaria castellano-leonesa sólo estudia la religiosa.

${ }^{52}$ G. MARTíNEZ DíEZ, Los templarios en la Corona de castilla, cit. n. 6.

${ }^{53}$ J. CASTÁN LANASPA, Arquitectura templaria, cit. n. 50, p.31.
} 
han aparecido algunos artículos de desigual valía dedicados a la arquitectura militar del Temple ${ }^{54}$.

En los últimos años parece consolidarse la metodología propuesta por Lambert en trabajos de investigación, a menudo promovidos desde la Universidad, dedicados a la arquitectura de los templarios, que van apareciendo en misceláneas o en actas de congresos.

En el simposio «El arte y las Órdenes Militares» ${ }^{55}$, hubo una aportación que representa una primera aproximación al conocimiento de la arquitectura militar del Temple en la región extremeña. Nos referimos a los artículos sobre las fortalezas de Jerez de los Caballeros ${ }^{56}$ y Alcorchón $^{57}$.

También en el «VIII Congreso Nacional de Historia del Arte» ${ }^{58}$ se incidió en el legado monumental de la orden del Temple en la región extremeña; en esta ocasión por parte de J. Pizarro Gómez, que presentó un primer inventario de fortalezas (Trevejo, Cória, Alconétar, Alconchel, Jerez de los Caballeros, Burguillos, Higuera de Vargas, Fregenal de la Sierra, Capilla, Almorchón, Puebla de Alcocer) y algunas iglesias parroquiales ${ }^{59}$. Como consecuencia de esta labor investigadora, dos años más tarde, se editarán dos guías turísticas en las cuales los castillos templarios tienen un papel relevante ${ }^{60}$.

Un libro importante de síntesis de reciente aparición sobre los templarios en la corona de Castilla, al que nos hemos referido en más de una ocasión, es el del erudito jesuita G. Martínez Díez, publicado en $1993^{61}$. Aunque no es su intención el estudio específico de la arquitectura templaria, al plantear el estudio histórico de las encomiendas castellanas, se refiere forzosamente a los edificios de la Orden. En conjunto, el estudio resulta una panorámica muy completa de los asentamientos templarios de la Corona castellana que se echaba de menos en la bibliografía. Uno tiene la impresión de que en esta obra se desvelan muchas de las dudas endémicas que la falta de documentación del Temple castellano ha suscitado; circunstancia que, inexorablemente, conduce al autor a descalificar hipótesis anteriores. Así vemos como desvincula de la Orden monumentos importantes como las

${ }^{54}$ J.L. GORDILlo COURCIERES Dos castillos turolenses casi desconocidos: Cantavieja. Castellote, en Castillos de España, 13 (80) Madrid, 1976, pp.21-33; E. LIAÑO; M.J. RAMON; M. J. VILLARO, El castillo de Monzón, en Castillos de Espana, 66, Madrid, 1969, pp.281-309; fortaleza templaria en la provincia catalano-aragonesa de la Orden, en Castillos de España, 101, Madrid, 1993, pp.17-32;...

${ }^{55}$ Actas del Simposio "El arte y las órdenes militares", Cáceres, 1985.

${ }^{56}$ M. GARRIDO SANTIAGO, La fortaleza de Jerez de los Caballeros, ibidem, pp.73-90.

${ }^{57}$ J.L. PASTOR ZAPATA; A. RUIBAL RODRÍGUEZ, Una fortaleza de las órdenes militares: el castillo de Almorchón, Ibidem, pp. 203-226.

${ }^{58}$ Actas del VIII Congreso Nacional de Historia del Arte, Cáceres, 3-6 de octubre 1990, v. I, Mérida, 1992.

${ }^{59}$ F.J. PIZARRO GÓMEZ, La expansión artística en la frontera hispano-musulmana. La Orden del Temple en Extremadura, Ibidem, pp. 109-118.

${ }^{60} \mathrm{~J}$. PIZARro Gómez, Por tierras de Badajoz, León, Ed. Lancia, 1992 y M ${ }^{\mathrm{a}}$ T. TERróN REYNOLDS, Castillos de Badajoz, León, Ed. Lancia, 1992.

${ }^{61}$ G. MARTínez DíEZ, Los templarios en la Corona de Castilla, cit. nota 5. 
iglesias de Villamuriel de Cerrato (Palencia) ${ }^{62}$, San Bartolomé de Ucero ${ }^{63}$ y San Polo (Soria) ${ }^{64}$ - todas ellas estudiadas por Castán-; o como pone en duda la «templaridad», siempre polémica, de la Vera Cruz de Segovia ${ }^{65}$.

Otras aportaciones hubo en el «IX Seminario sobre Historia del Monacato» de Aguilar de Campoo ${ }^{66}$ y en la «XV Asamblea General de la Sociedad Española de Estudios Medievales ${ }^{67}$. El seminario de Aguilar incluye una ponencia de Castán ${ }^{68}$ que quiere ser un ensayo de síntesis sobre la arquitectura de las órdenes militares en Castilla; en su mayor parte se refiere a los edificios de culto, sobre todo templarios, que había tratado en trabajos anteriores $^{69}$. Omite los edificios cuestionados por Martínez Díez ${ }^{70}$ aunque insiste en la problemática de la Vera $\mathrm{Cruz}^{71} \mathrm{y}$, como en su trabajo anterior de $1983^{72}$, sin justificarlo, insiste en minimizar el papel de las órdenes en la construcción de castillos en la Península. La XV Asamblea de la SEEM fue un monográfico dedicado a La fortaleza medieval, realidad y símbolo ${ }^{73}$; en la cual fueron presentadas dos intervenciones que parcialmente interesan a la arquitectura del Temple; una de M.J. Barroca ${ }^{74}$ será vista más adelante, al tratar de Portugal, y otra ${ }^{75}$ que entre diversos ejemplos analiza la fortaleza templaria de Fregenal de la Sierra (Badajoz) como muestra de tipología gótica, con elementos novedosos.

La colaboración de la arqueología en la investigación castellológica, tan deseable como rara en la península, ha producido recientemente un trabajo

\footnotetext{
${ }^{62}$ Ibidem, p. 146.

${ }^{63}$ Ibidem, p. 141.

${ }^{64}$ Ibidem, p. 141.

${ }^{65}$ Según MARTínEZ DíEz (Ibidem, p. 156) el documento aportado por CABELlo DORDERO ( $\mathrm{La}$ iglesia de la Vera Cruz, cit. $n$. 15) para afirmar la filiación templaria del edificio es «una burda falsificación». Es de notar que estudiosos como Lambert, Cocheril, Oursel, Dailliez... han considerado templaria la iglesia de la Vera Cruz, a partir del articulo de Cabello Dordero.

${ }^{66}$ Los monjes soldados. Los templarios y otras órdenes militares. "Actas del IX Seminario sobre Historia del Monacato (7-10 de agosto de 1995)", Aguilar de Campoo, 1996.

${ }^{67}$ J.A. BARRIO BARRIO Y J.V. CABEZUELO PLIEGO (eds.), La fortaleza medieval, realidad y símbolo, «Actas de la XV Asamblea General de la Sociedad Española de Estudios Medievales»,

${ }^{68} \mathrm{~J}$. CASTÁN LANASPA, La arquitectura de las órdenes militares en Castilla, en Los monjes soldados, cit. n. 66, pp. 135-152.

${ }^{69} \mathrm{El}$ libro citado de 1983 (La arquitectura templaria castellano-leonesa..., cit. n. 50) y el artículo, Las órdenes militares y su arquitectura, en «Jornadas sobre el románico en la provincia de Palencia», Palencia, 1986, pp. 47-55).

${ }^{70}$ Los templarios en la corona de Castilla, cit. n. 6.

${ }^{71}$ Que no cesa de campear, pues recientemente Rincón arremete en pro de la paternidad de los canonigos del Santo Sepulcro (W. RINCÓN GARCÍA, Aspectos artísticos de la Orden del Santo Encontro sobre Ordens Militares . Palmela, 22 a 25 de Janeiro de 1998", 2, Edições Colibri, Camara Municipal de Palmela, 1999, pp. 419-426).

${ }^{72}$ La arquitectura templaria, cit. n. 50.

${ }^{73}$ Cit. n. 67.

${ }^{74}$ M.J. BARROCA, Castelos medievais portugueses. Origens e evoluçao (séc. IX-XIV), en La fortaleza medieval, cit. n. 67, pp. 13-30.

${ }^{75} \mathrm{M}$. VALOR PIECHOTTA, Las fortificaciones de la banda gallega: algunos ejemplos de las provincias de Huelva y Badajoz y del Alentejo portugués, Ibidem, pp. 91-108.
} 
interesante sobre el castillo de Ponferrada ${ }^{76}$. En él se platean hipótesis nuevas sobre las etapas de construcción de la fortaleza, en las que el castillo templario habría quedado limitado a una modesta cerca. Opinión que no compartimos por estimar que no se han analizado con profundidad ciertos restos arquitectónicos, claramente del siglo XIII, que forman parte del "castillo nuevo".

En las últimas décadas se han publicado artículos y guías dedicadas al castillo templario de Peníscola. Presentan una novedad con relación a los trabajos anteriores ${ }^{77}$ : por fin se reconoce y valora el edificio como construcción templaria (antes sólo se hablaba del papa Luna). Son las guías de J.B. $\operatorname{Simó}^{78}$ (1982 y 1990) y los artículos de A. Zaragozà y M. García Lisón, en el «Catàleg de Monuments i Conjunts de la Comunitat Valenciana» ${ }^{79}$ y en la revista «Peñíscola ciudad en el mar» ${ }^{80}$. Recientemente, en un artículo de J. Fuguet $^{81}$, han sido puestas de relieve las concomitancias estructurales y formales que presentan las fortalezas de Miravet y Peníscola y su relación con la arquitectura de las órdenes militares en Tierra Santa.

También en los últimos años ha habido actividad editorial en relación al patrimonio arquitectónico aragonés, religioso y militar, que incluye los castillos templarios de Monzón y Castellote, entre otros. Nos referimos a los estudios de castellologia aragonesa de Gordillo ${ }^{82}$ y C. Guitart ${ }^{83}$.

Mucha información, aunque dispersa y confusa, sobre el castillo de Monzón contiene un libro publicado por F. Castillón ${ }^{84}$. Sin menoscabar la riqueza documental del libro, el autor se equivoca gravemente cuando, tras descalificar implícitamente a los historiadores de la arquitectura que han tratado el tema ${ }^{85}$, pretende demostrar documentalmente que un edificio de la fortaleza, que a todas luces (por ubicación, por tipología, por estructura) debió ser refectorio o sala de caballeros, había sido la iglesia parroquial de San

${ }^{76} \mathrm{~F}$. Cobos Guerra; J.J. De Castro Fernández, Castillo de Ponferrada, Edilesa, Trobajo del Camino (León), 2002 .

${ }^{77}$ C. Sarthou Carreres, Castillos de España, cit. n. 24; L. Tramoyeres Blasco, Castillos valencianos, cit. n. 25; A. BELTRAN MARTINEZ, Breve historia de Peñíscola y del castillo del valencianos, cit. n. 25; A. BELTRAN MARTINEZ, B.
Papa Luna, Zaragoza, Ed. Librería General, 1972.

${ }^{78}$ J.B. Simó CASTILlo, Peñíscola. Ciudad histórica y morada del Papa Luna, Barcelona, Avesta, 1982; IDEM, El castillo templario-pontificio de Peñíscola, Vinaròs Ed. Els Diaris S.A.

${ }^{79}$ M. GARCía-Lisón; A. ZARAGOZÀ, Peníscola, en «Catàleg de Monuments i Conjunts de la Comunitat Valenciana», Conselleria de Cultura, Generalitat Valenciana, Valencia, 1983, p.14-29.

${ }^{80}$ M. GARCía-Lisón; A. ZARAgOZÁ, Documentación gráfica referida a Peñíscola, Siglo XVIII-1, Peñíscola. Ciudad en el mar, 61, pp. 16-25.

${ }^{81}$ J. Fuguet SANS De Miravet (1153) a Peñiscola, cit. n. 54. El mismo artículo en F. TOMMASI, ed., Acri 1291. La fine della presenza degli ordini militari in Terra Santa e i nuovi orientamenti nel XIV secolo, Perusa, 1996, pp. 43-67.

${ }^{82} \mathrm{~J}$.L. GORDILlo COURCIERES, Castillos templarios arruinados en el sur de la Corona de Aragón, Valencia, Ed. Prometeo, 1974; IDEM, Dos castillos, cit. n. 54.

${ }^{83}$ C. Guitart Aparicio, Castillos de Aragón, I-II, Zaragoza, Ed. Librería General, 1976.

${ }^{84}$ F. CASTILLÓN CORTADA, El castillo de Monzón, Zaragoza, 1989.

${ }^{85}$ E. LIAÑo ET ALII, El castillo de Monzón, cit. n. 54, p. 300; C. GUITART APARICIO, Castillos de Aragón, cit. n. 83, II, pp. 45-50; J. FUGUET SANS, L' arquitectura dels templers, cit.', n. 3 , p. 85 . 
Juan $^{86}$. Recientes excavaciones del Centro de Estudios de Monzón han descubierto en la ladera sur de la colina donde se yergue el castillo, los cimientos de la antigua iglesia de San Juan, validando de esta forma aquel refrán que previene sobre lo engañosas que pueden ser las apariencias (aunque sean documentales).

De particular interés para la arquitectura templaria peninsular fue la excavación de urgencia, llevada a cabo en 1991, en el solar donde hasta los años sesenta del siglo XIX, se levantara la capilla conventual del Temple de Zaragoza. Sabíamos por fuentes contemporáneas a su destrucción ${ }^{87}$, que se trataba de uno de los raros ejemplos peninsulares de planta circular. J.F. Casabona, director de la excavación ha escrito sobre ello ${ }^{88}$.

Interesante es la monografía que, recientemente (1997), Olga Pérez Monzón ha dedicado a la encomienda zaragozana de Novillas ${ }^{89}$; es un trabajo eminentemente documentalista -elaborado a partir de la documentación hospitalaria de época moderna-, que ofrece alguna información sobre la capilla y el castillo de la antigua encomienda templaria, hoy desaparecidos o remodelados por los sanjuanistas.

A lo largo de la última década de este pasado siglo, en la aragonesa localidad de Ambel, sede de una importante encomienda templaria y hospitalaria, se llevó a cabo un ambicioso proyecto de arqueología medieval bajo la dirección del doctor Chistopher Gerrard, de la universidad de Durham, profundo conocedor de la zona. El estudio ha sido decisivo para conocer las fases constructivas de la casa-encomienda templaria y hospitalaria ${ }^{90}$.

También en Mallorca se ha escrito en estos últimos años sobre los monumentos templarios que aún se conservan. En 1954 publicaron un opúsculo F. Esteve y G. Alomar acerca de algunas iglesias de la repoblación, entre ellas la capilla de la encomienda de Palma ${ }^{91}$; años después, F. Lladó Pol, estudió el aspecto militar de esta misma sede ${ }^{92}$. Recientemente (1995), en el congreso que periódicamente celebra la Societat Arqueològica Lul-liana, J. Segura Salado da cuenta de las vicisitudes sufridas, a fines del siglo XIX,

${ }^{86}$ Error que, inexplicablemente defiende Sans i Travé (J.M. SANS I TRAVÉ, Els templers, de la rosa a la creu, Lérida, 1996, pp. 374-378).

${ }^{87} \mathrm{P}$. MADOZ, Diccionario Geográfico-Estadístico-Histórico de España y sus posesiones en Ultramar, vol. XVI, Madrid, 1850 , p.585.

${ }^{88}$ J.F. CASABONA SEBASTIÁN, La excavación de la Iglesia del Temple de Zaragoza, en «Arqueología Aragonesa», 1991 , Zaragoza, 1994, pp. 275-278; J.F.C[ASABONA]S[EBASTIÁN], Temple,

${ }^{89}$ O. PÉrEZ Monzón, La encomienda de Novillas y su pasado artístico, Borja, Centro de Estudios Borjanos, 1997 (Agradezco a A. Luttrell el conocimiento de esta publicación).

${ }^{90} \mathrm{C}$. GERRARD, Paisaje y señorío: La casa conventual de Ambel (Zaragoza), en Arqueología, arquitectura e historia de las Ordenes militares del Temple y del Hospital, Zaragoza, Institución «Fernando el Católico» (CSIC), 2003.

${ }^{91} \mathrm{~F}$. ESTEVE; G. AlOMAR, Pequeñas iglesias de los repobladores de Mallorca (siglos XIII y $X I V)$, Palma de Mallorca, Imprenta Talleres de Mossén Álcover, 1954.

${ }_{92}^{92} \mathrm{~F}$. LLADÓ POL, Aproximación històrico-artística a la fortaleza del Temple, Quaderns ARCA, 1989, t. 5 , pp. 1-18. A pesar de las expectativas del título, el estudio se limita a la cerca medieval, de la cual apenas queda nada. 
por la casa encomienda mallorquina, en especial por la capilla ${ }^{93}$. Mas recientemente, año 2000, en un congreso internacional, organizado por la Acadèmia Mallorquina d'Estudis Genealògics, Heràldics i Històrics, Antonio Mut Calafell y $\mathrm{M}^{\mathrm{a}}$ José Massot Ramis de Ayreflor presentaron una interesante ponencia que permite conocer el aspecto que tenia dicha sede en el siglo XIV, poco después que fuera transferida a la Orden del Hospital ${ }^{94}$.

Durante las últimas décadas, en Cataluña, se han publicado numerosas monografías sobre castillos de los templarios, que, en su mayor parte, inciden en la historia sin apenas tratar la arquitectura. Entre ellas podemos destacar la de A. Bladé sobre el castillo de Miravet ${ }^{95}$; la que dedicaron a la fortaleza de Gardeny, en su obra sobre castillos medievales catalanes, Luís Monreal y Martí de Riquer ${ }^{96}$; el artículo relativo a esta misma fortaleza de Lérida de M. García y Serramona ${ }^{97}$. Un caso especial de trabajo monográfico, que sigue un criterio historiográfico similar a los anteriores, es la obra monumental Els Castells Catalans (1967-1979) redactado en su mayor parte por P. Català y Roca, donde se puede hallar cumplida información sobre todas y cada una de las fortalezas templarias catalanas ${ }^{8}$. También han visto la luz algunos estudios sobre capillas que fueron de la Orden (conventuales o parroquiales) W. Rincón et alt ${ }^{99}$, la antigua parroquial de Vilalba dels Arcs, en la Terra Alta, Tarragona; J. Ventosa ${ }^{100}$ algunas parroquiales de fundación templaria de la encomienda de Miravet; J. Fuguet ${ }^{101}$, las capillas templarias de la Catalunya Nova...

Una primera aproximación de conjunto a la arquitectura templaria catalana corresponde a N. de Dalmases y A. José y Pitarch ${ }^{102}$. A pesar de que el tema supone solamente un pequeño apartado en el conjunto de una obra que trata el arte catalán del siglo XIII, es la primera vez que la arquitectura de los templarios es tratada en los mismos términos que la de otras órdenes religiosas

${ }^{93}$ J. SEgura SALADO, El castell del Temple, «Actes del III Congrés. El nostre patrimoni Cultural: El patrimoni Tudat (1836-1994)», Palma de Mallorca, Societat Arqueologica Lul-liana, 1995, pp. 281-290 y 405-410.

${ }^{94}$ Aportación documental y gráfica sobre los bienes de los templarios de Mallorca transferidos a la Aportación de San Juan de Jerusalén y en particular sobre la fortaleza del Temple de la ciudad de Mallorca (1315-1988), en L'Orde de Malta, el Regne de Mallorca i la Mediterrania ( ¿Congrés científicic internacional», Ponències , Palma, 25-28 d'octubre de 2000, Govern de les Illes Balears, Conselleria de Cultura, pp. 117-159.

${ }^{95}$ A. BladÉ I Desumvila, El castell de Miravet, Barcelona, R. Dalmau Ed., 1966.

${ }^{96} \mathrm{~L}$. MONREAL; M. DE RIQUER, Els castells medievals de Catalunya, III, Barcelona, 1965, pp. $275-295$

${ }^{97} \mathrm{M}$. García I Serramona, Santa Maria de Gardeny, «Ilerda», XLIV (Lérida, 1983), pp. 245-268

${ }^{98}$ Els Castells Catalans, Barcelona, R. Dalmau, Ed., 1967-1979, I-VI.

${ }^{99}$ W. RinCón; A. ROMERO; J. FERRER, La iglesia gótica de Nuestra Señora de Gracia y las Ordenes Militares del Temple y de Sant Juan de Jerusalén en Vilalba dels Arcs, Zaragoza, Unali, 1981

${ }^{100}$ E. VENTOSA I SERRA, Esglésies singulars de la Terra Alta, Tarragona, Diputació de Tarragona, 1986

${ }^{101}$ J. FUGUET SANS, Arquitectura de les capelles templeres a la Catalunya Nova, «Aplec de Treballs del Centre d'Estudis de la Conca de Barberà», 9, (Montblanc, 1989), pp.5-52.

${ }^{102}$ Véase la n. 2. 
(cistercienses, cartujos, hospitalarios, franciscanos). Los autores esbozan el estado de la cuestión hasta los estudios de Lambert y dedican principalmente la atención a las fortalezas de Gardeny, Miravet y Peníscola.

En el año 1989 se presentó en la Universidad de Barcelona una tesis doctoral sobre la arquitectura templaria en Cataluña ${ }^{103}$; se trataba del primer estudio de conjunto realizado sobre todas las construcciones templarias de un territorio. La metodología siguió, en buena medida, las propuestas de Lambert, es decir, después de una investigación histórica basada en la bibliografía y la documentación de archivo, se delimitaron con exactitud las posesiones de la orden del Temple y se pudo realizar el inventario de todas las construcciones, existentes y desaparecidas. El corpus obtenido fue analizado y comparado con la arquitectura general contemporánea del país, con las construcciones templarias de los países vecinos y con las fortalezas de los cruzados de Síria y Palestina. A partir de ello se establecieron estilos, tipologías, influencias, peculiaridades... Entre las conclusiones se constataron relaciones (influencias o paralelismos) entre la arquitectura militar templaria catalana y las fortalezas de los cruzados de Oriente, en la utilización de plantas cuadrangulares, dobles recintos... así como en la organización funcional de los conjuntos conventuales y en la tipología de los edificios.

Con posterioridad a esta tesis sobre la arquitectura templaria catalana, han aparecido diversos trabajos del mismo autor que amplían o modifican algún aspecto allí estudiado ${ }^{104}$; algunos artículos monográficos, de diversos autores, en una obra colectiva («Catalunya Romànica») $)^{105}$; y un libro sobre los templarios en el Rosellón (Vinas, 2001) ${ }^{106}$ con interesantes comentarios sobre los edificios templarios allí existentes.

La historiografía portuguesa de los últimos años, en general, ha seguido la línea iniciada en la primera mitad del siglo XX, marcada por la preeminencia de Tomar y la singularidad de Almourol. En general han sido

\footnotetext{
${ }^{103}$ J. FUGUET SANS, L'arquitectura dels templers, cit. n. 3.

${ }^{104}$ J. FugUEt SANS, Templers $i$ hospitalers, I. Guia del Camp de Tarragona, la Conca de Barberà, la Segarra i el Solsonès, Barcelona, Rafael Dalmau, Ed., 1997; IDEM, Templers Hospitalers II. Guia de les Terres de l'Ebre i dels castells templers del Baix Maestrat, Barcelona, Rafael Dalmau, Ed., 1998; IDEM, Templers $i$ Hospitalers, III. Guia de les Terres de Ponent i de la Franja, Barcelona. Rafael Dalmau, Ed., 2000; IDEM, L'arquitectura dels templers a la "Catalunya Nord" en VV. AA., Les templiers en Pays Catalan, Perpiñán, Ed. E Trabucaire, 1998, pp. 159-213; IDEM, L'architecture militaire des commanderies templieres de la Couronne d'Aragon, en A.LUTRELl; L.PRESSOUYRE (dir.), La Commanderie Institution des ordres militaires dans l'Occident médieval («Premier Colloque international du Conservatoire ordres militaires dans
Larzac Templier et Hospitalier»), Paris, Editions du CTHS, 2002, pp.187-216.

${ }^{105} \mathrm{~J}$. FUGUET I SANS, Castell de Barberà, en Catalunya Romànica, XXI, FEC, Barcelona 1995, pp. 463-466; F. ESPANOL BERTRÁN; J. FUGUET SANS, Sant Joan del castell de Barberà abans Sant Salvador), en Catalunya Romanica, XXI, FEC, Barcelona 1995, pp.466-467; J. FUGUET I SANS; C. PUIGFERRAT I OLIVA; M. MACIÄ I GOU; J.L. RIBER I FOGUET, Castell de Vallfogona de Riucorb. Santa Maria de Vallfogona de Riucorb, en Catalunya Románica, XXI FEC Barcelona 1995, pp. 550-553; M.L. RAMOS I MARTÍNEZ; J. FUGUET I SANS, Castell de Gardeny, en Catalunya Romanica, XXIV. FEC, Barcelona 1997, pp. 196-201; P.L. ARTIGUES I CONESA; J. BOLOOS I MASCLANS; J. FUGUET I SANS: Miravet. Castell de Miravet. Santa Maria del castell de Miravet, en Catalunya Romànica, XXVI, FEC, Barcelona, 1997, pp. 190-197.

${ }^{106} \mathrm{R}$. VINAS, L'Ordre du Temple en Roussillon, Canet, Ed. Trabucaire, 2001.
} 
trabajos monográficos, artículos, capítulos en obras generales ${ }^{107} \ldots$ que no presentan excesiva novedad en materia arquitectónica. Constituyen una excepción, en este sentido, los artículos publicados, recientemente, en la revista "Portugalia" de la Universidad de Oporto por Mario Jorge Barroca ${ }^{108}$. En ellos se aprecia como Portugal, a diferencia de Castilla, posee abundante documentación para el estudio de sus fortalezas templarias; no sólo de archivo, sino también epigráfica (casi todas las encomiendas militares del Temple tienen epígrafes conmemorativos donde se lee el nombre del promotor de la construcción y la fecha). Barroca estudia y analiza las fortalezas de Tomar, Almourol, Pombal, Soure... las data con precisión y subraya la aparición de dos elementos nuevos con relación a la arquitectura militar portuguesa de la época: la torre del homenaje, grande y aislada, en el interior del recinto y el alambor en torres y murallas ${ }^{109}$. En la XV Asamblea de la SEEM (1998), el mismo autor, incide de nuevo en estos, y otros, aspectos novedosos de la arquitectura templaria portuguesa ${ }^{110}$.

Para concluir no podemos dejar de referirnos al artículo «Templari» que ha redactado Antonio Cadei para la Enciclopedia dell'arte Medievale $e^{111}$. Se trata de un trabajo de síntesis que, entre otros aspectos artísticos de la orden del Temple, trata de su arquitectura en general, la de Oriente y la de Occidente, atendiendo a diversos conceptos (los centros de la Orden, la protección de los peregrinos, la arquitectura militar, la casa rural y la arquitectura sacra). El estudio, de la misma naturaleza que una ponencia que presentó el autor en un anterior coloquio ${ }^{112}$, mezcla de erudición e intuición, significa la aportación más completa de conjunto sobre la arquitectura templaria que hasta la fecha se ha escrito.

\footnotetext{
${ }^{107}$ Sobre Tomar: A. RoSA, Historia de Tomar, v. I, Tomar, 1965; M.S. ALvES CONDE, Tomar medieval. O espaço e os homens, Cascais, 1969; J.A. FRANÇA, Tomar, Ed. Presença, Tomar, 1994; Sobre Tomar: D. PERES, A gloriosa historia dos mais belos castelos de Portugal Portucalense Editora. Porto, 1969 , pp.161-166; C.A. FERREIRA DE ALMEIDA, O Románico, en Historia da Arte em Portugal, v. III, Ed. Alfa, Lisboa, 1986, pp. 118-120... Sobre Almourol: A. GONÇALVES DA COSTA, O castelo de Almourol e o Turismo, en Livro do Congresso. Primeiro Congresso sobre monumentos militares portugueses, Lisboa, 1982, pp.14-20; J.J. ALVES DIAS, As comendas de Almourol e Cardiga dos Ordens do Templo e de Cristo na Idade Media, en As Ordens Militares em Portugal, Actas de $1^{\circ}$ Encontro sobre Ordens Militares Palmela, 1991 , pp.101-112; D. PERES, A gloriosa historia dos mais belos castelos de Portugal, Porto, Portucalense Editora, 1969, pp. 167-176.

${ }^{108} \mathrm{M}$. J. BARROCA, Do castelo da reconquista ao castelo románico (séc. IX a XII), «Portugalia, Nova Série», XI-XII, (Porto, 1990/1991), pp. 89-136; IDEM, A ordem do Templo e a arquitectura militar portuguesa do século XII, «Portugalia, Nova Série», XVII-XVIII, (Porto, 1996/1997), pp.171-209.

${ }^{109}$ La Torre del Homenaje habría sido difundida en Portugal por los templarios, y el uso del alambor es visto como una influencia directa de la arquitectura militar de Tierra Santa, traída por los mismos caballeros.

${ }^{110}$ M.J. BARROCA, Castelos medievais portugueses. Origens e evolução (séc. IX-XIV), en, J.A. BARRIO BARRIO; J.V. CABEZUElO PLIEGo (eds.), La fortaleza, cit. n. 67, pp. 13-30.

${ }^{111}$ A. CADEI, Templari, en Enciclopedia dell'arte Medievale, v. XI, Roma, Istituto della Enciclopedia Italiana, 2000, pp. 86-110.

${ }^{112}$ A. CADEI, Architettura sacra templare, en G. VITI; A. CADEI; V. AsCANI CABELlO

DORDERO, La iglesia de la Vera Cruz, «Estudios Segovianos», 3, (Segovia, 1951), pp. 425 448). Monaci in armi. L'architectura sacra dei Templari attraverso it Mediterraneo, Certosa di Firenze, 1995, pp.15-170.
} 
Si bien actualmente los estudios sobre arquitectura militar están bastante avanzados en Portugal y en la Corona de Aragón, el reino de Castilla presenta un déficit historiográfico que no permite hacer comparaciones con el resto de construcciones templarias de la Península y establecer si también sus edificios presentan elementos novedosos respecto a su tiempo. Sería deseable que en el futuro se profundizara en el conocimiento de toda la arquitectura militar templaria de la Corona de Castilla y de la Península en general. En particular en lo referente al régimen de tenencia de los castillos templarios castellano-leoneses. Sólo así podremos ver si existen diferencias entre los castillos templarios castellanos por una parte y los portugueses y de la Corona de Aragón por otra. Mientras tanto no nos parece oportuno afirmar que en Castilla y León los templarios no aportaron nada en arquitectura militar.

Fecha de recepción del artículo: mayo 2006

Fecha de aceptación y versión final: enero 2007 